\title{
Consciência morfológica e ortografia. Uma relação para além da consciência fonológica?
}

\section{Morphological awareness and spelling. A relationship beyond phonological awareness?}

\section{La conciencia morfológica y la ortografía. Una relación más allá de la fonológica?}

\author{
Silvia Brilhante Guimarães* \\ Universidade Salgado de Oliveira - Universo, Rio de Janeiro, Rio de Janeiro, Brasil
}

\section{Márcia Maria Peruzzi Elia da Mota**}

Universidade do Estado do Rio de Janeiro - UERJ, Rio de Janeiro, Rio de Janeiro, Brasil

\section{RESUMO}

Este estudo investigou a contribuição única da consciência morfológica em palavras com diferentes regras ortográficas no português do Brasil. Participaram do estudo 114 crianças do $2^{\circ}$ e $4^{\circ}$ ano do Ensino Fundamental de uma escola pública. As crianças foram avaliadas quanto ao seu conhecimento ortográfico por meio de um ditado de palavras com diferentes dificuldades ortográficas (regras contextuais, morfológicas e palavras irregulares), consciência fonológica, consciência morfológica e inteligência (verbal e não verbal). Os resultados mostraram que, para ortografia de palavras com regras contextuais, morfológicas e irregulares, a consciência morfológica tem uma contribuição pequena, mas independente da consciência fonológica. A contribuição da consciência fonológica foi maior nas palavras contextuais e morfológicas. Nas palavras com ortografias irregulares, a contribuição da consciência morfológica foi maior do que a fonológica. Esses resultados sugerem que o conhecimento explícito das unidades mínimas de significado na palavra pode ser uma habilidade chave para o desenvolvimento da ortografia.

Palavras-chave: consciência morfológica, consciência fonológica, ortografia.

\begin{abstract}
This study investigates the unique contribution of morphological awareness in the different spellings of the Portuguese in Brazil. The study included 114 children of 2 and 4 years of elementary education at a public school. The children were evaluated on orthographic knowledge measure by spelling test with different orthographic difficulties, phonological awareness, morphological awareness, verbal and nonverbal cognitive abilities. The results showed that morphological awareness has a small but independent contribution of phonological awareness for spelling words with contextual, morphological and irregular rules. The influence of phonological awareness
\end{abstract}


was higher in contextual and morphological words. In the words with irregular spellings, morphological awareness of the contribution was higher than the phonological awareness. These results suggest that awareness of minimum units of meaning in the word can be a key skill for the spelling development.

Keywords: morphological awareness, phonological awareness, spelling.

\begin{abstract}
RESUMEN
Este estudio investigó la contribución única de la conciencia morfológica en palabras con diferentes reglas ortográficas en el portugués de Brasil. El estudio incluyó a 114 niños de 2 y 4 años de educación primaria en una escuela pública. Los niños fueron evaluados en cuanto a su conocimiento ortográfico por medio de un dictado de palabras con diferentes dificultades ortográficas (reglas contextuales, morfológicas y palabras irregulares), conciencia fonológica, conciencia morfológica e inteligencia (verbal y no verbal). Los resultados mostraron que la conciencia morfológica tiene una pequeña contribución más independiente de la conciencia fonológica de las palabras de ortografía contextuales y reglas morfológicas irregulares. El influencia de la conciencia fonológica fue mayor en palabras contextuales y morfológicos. En las palabras con ortografía irregular conciencia morfológica de la contribución era más alta que la conciencia fonológica. Estos resultados sugieren que el conocimiento explícito de las unidades mínimas de significado en la palabra puede ser una habilidad clave para el desarrollo de la ortografía.
\end{abstract}

Palabras clave: conciencia morfológica, conciencia fonológica, ortografía.

\title{
1 Introdução
}

A língua portuguesa pode ser considerada morfofonêmica, ou seja, uma língua pautada tanto por fonemas, menores unidades de som na palavra, como também por morfemas, unidades mínimas de significado na palavra (Laroca, 2005). A representação ortográfica das palavras faladas do português não se sustenta apenas pela relação letra e som, requerendo do aprendiz trabalhar com unidades de significado, os morfemas. Muitos vocábulos contêm sons que podem ser escritos em mais de uma forma. Por exemplo, embora as palavras "chatice" e "dormisse" compartilhem o mesmo som final /ise/, há uma informação de ordem gramatical que as distingue. 0 morfema "ice" indica substantivo abstrato e, no morfema "isse", "i" indica a conjugação e "sse" a desinência do imperfeito do subjuntivo. De acordo com os estudos de Seymour (2005) e Seymour, Aro e Erskine (2003), as línguas alfabéticas variam em relação à complexidade e consistência entre grafemas (letras) e fonemas (sons). As línguas alfabéticas podem ser classificadas ao longo de uma dimensão de complexidade silábica e profundidade ortográfica. Nos sistemas alfabéticos rasos ou transparentes, a consistência entre letra e som é unívoca, ou seja, direta. Há um som para uma letra. Quando essa relação torna-se complexa, ou seja, um fonema sendo representado por mais de um grafema e vice-versa, o nível de 
complexidade da língua aumenta em direção à profundidade ortográfica. Nesse caso, quanto mais a língua caminha em direção à complexidade entre as relações entre fonema e grafema, mais profunda se torna. O português é considerado de natureza silábica simples, mas está no meio do espectro de complexidade ortográfica, apesar de ser mais transparente do que 0 inglês, possui ambiguidades na grafia, muitas delas que podem ser resolvidas pelo conhecimento da estrutura morfológica das palavras. Há evidências de que refletir sobre a linguagem, sobre a consciência metalinguística ajuda no aprendizado das correspondências entre letra e som e também aspectos da complexidade ortográfica (Gombert, 2003).

Vários estudos têm fornecido evidências de que refletir sobre a linguagem (consciência metalinguística) é conquista primordial para a alfabetização (Bradley \& Bryant, 1983; Nunes, Bindman, \& Bryant, 1997). Especialmente, a capacidade do aprendiz de manipular explicitamente os segmentos da fala, a consciência fonológica parece ser o ponto chave para aquisição e desenvolvimento da leitura e escrita (Bradley \& Bryant, 1983; Cardoso-Martins, 1995; Maluf \& Barrera,1997; Mann \& Liberman 1984). Entretanto, outros estudos apontam que as crianças também pensam em unidades de significado, como os morfemas, para auxiliá-las no armazenamento da ortografia da palavra na memória (Nunes et al., 1997; Nunes \& Bryant, 2006; Nunes, Bryant, \& Olsson, 2003). Essa habilidade é chamada consciência morfológica.

Segundo Carlisle (1995), a consciência morfológica significa refletir e manipular intencionalmente sobre os morfemas. Os morfemas são considerados unidades mínimas significativas ou dotadas de significado que integram as palavras (Bechara, 2009). Por exemplo, a palavra "tristeza" é dividida no radical "trist- + -eza". Os morfemas podem assumir a função derivacional e flexional. A derivação tem uma função semântica constituída basicamente pela formação de palavras, a partir de uma palavra primitiva + os afixos (sufixos ou prefixos, ou sufixos e prefixos ao mesmo tempo). Por exemplo, a palavra "portaria" possui dois morfemas "port-" + "-aria", o morfema "-aria" dá um novo significado a palavra "porta", designando lugar. $\mathrm{Na}$ função flexional, há uma variação sintática devido às exigências das concordâncias de gênero (masculino/feminino), número (singular/plural) e grau (diminutivo/aumentativo). Na palavra "gatos", o morfema "-os" caracteriza masculino e plural.

Dificuldades ortográficas, decorrentes das irregularidades na correspondência letra e som, podem ser superadas com 0 conhecimento dos morfemas. É o caso das palavras com morfemas homófonos que têm 0 mesmo som, mas ortograficamente são diferentes. Por exemplo, o som /eza/ em beleza/princesa; o som /ise/ em chatice /disse; o som /iu/ em fácil/dormiu. Em outros casos, a morfologia pode ser um caminho para ajudar o escritor na grafia de 
palavras derivadas. A palavra "pesado" é um adjetivo formado a partir da palavra "peso". Como a letra "s" entre as vogais tem som de $/ z /$, isso gera uma dúvida ortográfica. Assim, se a criança souber que "pesado" advém do radical "peso", mais o morfema "ado", pode grafá-la corretamente.

Vários modelos ortográficos apontam a necessidade de que os aprendizes superem uma fase alfabética (estabelecimento da relação letra e som) para avançarem na compreensão ortográfica, como propõem Ehri (2005), Seymor (2005), Nunes e Bryant (1997). Uma fase morfológica em língua com profundidade ortográfica, como é o caso do português, francês e inglês, é essencial para ajudar as crianças a darem conta da variabilidade do mapeamento entre som e ortografia da língua (Seymor, 2005). De acordo com Ehri (2005), a consolidação da fase alfabética permitirá às crianças estabelecerem conexões com morfemas para fixarem as grafias das palavras na memória.

Nesse sentido, a escrita de palavras com complexidade ortográficas envolve o processo cognitivo, tanto pela via da fonologia, quanto pela via da morfologia. Porém, alguns estudos têm indicado que a presença da consciência morfológica não está à sombra da consciência fonológica. A contribuição da consciência morfológica na escrita pode ocorrer independentemente da influência de outras habilidades cognitivas, a exemplo da consciência fonológica (Nunes et al., 1997; Deacon, Kirby, \& Casselman-Bell, 2009). Essa relação pode ser causal, como apontam alguns pesquisadores (Nunes et al., 2003; Nunes \& Bryant, 2006). Estudos de meta-análise de intervenção morfológica de Bowers, Kirby e Deacon (2010), Carlisle (2010), Goodwin e Ahn (2010) e Reed (2008), também reforçam evidências de que a instrução sobre a morfologia pode impulsionar as crianças na linguagem escrita, principalmente crianças com dificuldade de leitura de palavras e compreensão textual. Para Nunes e Bryant (2006), as crianças têm mais chance de ter sucesso na leitura e na escrita, se elas usarem a análise morfológica das palavras do que se recorrerem à estratégia fonológica ou à memorização.

Nunes et al. (1997) mostram que as crianças inglesas, dos seis aos dez anos de idade, utilizam-se do pensamento morfológico para escreverem os verbos do passado com o morfema "ed" cujo som da letra " $d$ " pode ser pronunciado pelos fonemas /t/ e /d/. Quanto maior o nível de consciência morfológica das crianças, maior seu sucesso na escrita dos verbos. Inicialmente, as crianças passam por uma fase de transcrição fonética até chegar ao uso correto do morfema. Deacon et al. (2009) ampliam essa discussão, ao encontrarem evidências preditivas da consciência morfológica na ortografia geral do inglês. Os resultados de suas pesquisas indicaram que o conhecimento explícito da morfologia, no início da aprendizagem ortográfica no $2^{\circ}$ ano, ajudou posteriormente 0 
conhecimento ortográfico no $4^{\circ}$ ano. Este foi um estudo importante, pois as pesquisadoras controlaram os efeitos de variáveis relevantes relacionadas à escrita, como a consciência fonológica, nomeação seriada rápida, vocabulário e inteligência. Mesmo nessas condições, a consciência morfológica teve uma contribuição pequena, mas significativa para a ortografia. Todavia, o estudo mediu apenas a ortografia geral. A hipótese que fica é se essa contribuição é específica a diferentes tipos de morfemas.

Na língua portuguesa, alguns estudos vêm discutindo a contribuição da consciência morfológica, para além da consciência fonológica na ortografia (Conti, 2010; Justi, 2009; Mota, Anibal, \& Lima, 2008). O estudo de Mota et al. (2008), com crianças do $2^{\circ}$ e $3^{\circ}$ anos do Ensino Fundamental, mostrou que a consciência morfológica derivacional contribuiu para a ortografia geral, depois do controle da idade e dos escores na tarefa de rima. Já o estudo de Conti (2010) avaliou, em 132 crianças do $2^{\circ}$ e $3^{\circ}$ anos do Ensino Fundamental, o efeito da consciência morfológica na escrita de palavras com diferentes tipos de regras ortográficas (geral, contextual, morfológica e irregular), após o controle da memória e da consciência fonológica. Os resultados evidenciaram que a consciência morfológica teve um efeito independente e significativo na ortografia geral e nas palavras com regras morfológicas, nas quais apenas a morfologia derivacional foi significativa. Resultados parecidos foram encontrados no estudo de Justi (2009) com crianças do $4^{\circ}$ ano. A consciência morfológica contribuiu para a escrita geral e para a escrita de palavras com regras morfológicas, após os controles da idade, inteligência, memória, nomeação seriada rápida e consciência fonológica. O interessante desse estudo é que os controles foram mais robustos do que os estudos de Conti (2010) e Mota et al. (2008) e, mesmo assim, apesar da diferença do ano escolar, a consciência morfológica foi significativa. Vale notar que, nos três estudos, a tarefa de ortografia geral foi a mesma.

A partir das evidências acima apresentadas, torna-se claro que o conhecimento sobre o papel da consciência morfológica no desenvolvimento da escrita não está compreendido em seus detalhes. No Brasil, é necessária a realização de Estudos, no intuito de desvendar a extensão da contribuição da consciência morfológica na ortografia do português. Nesse sentido, o presente trabalho se propõe a responder duas questões. A contribuição da consciência morfológica é única, para além da consciência fonológica em palavras com diferentes regras ortográficas no português? O efeito da consciência morfológica pode ser maior do que o da consciência fonológica para a escrita no português? 


\section{Método}

\subsection{Participantes}

Cento e quatorze crianças nos anos iniciais do Ensino Fundamental, sendo que 62 do $2^{\circ}$ ano ( $M=94,2$ meses; $D P=5$ meses) e 52 do $4^{\circ}$ ano do ensino fundamental de uma escola pública do Rio de Janeiro. O critério para inclusão das crianças na pesquisa foi a assinatura, pelos seus responsáveis, do Termo de Consentimento Livre e Esclarecido (TCLE). Esse termo seguiu as normas do Comitê de Ética e Pesquisa /UERJ - protocolo da pesquisa n 084.3.2012, parecer no 019/2013.

\subsection{Instrumentos}

\subsubsection{Habilidade verbal e não verbal}

- Wechsler Intelligence Scale for Children - WISC III (Wechsler, 1991): subteste de vocabulário e subteste de Cubos. Os coeficientes de fidedignidade para esses subtestes, calculados através do método de Guttmam, mostram bons índices de consistência interna (coeficientes maiores que 0,60 ), de acordo com o manual do teste. 0 índice de consistência interna (Guttman's) é $\lambda=0,79$ para o subteste de vocabulário e $\lambda=0,82$ para o subteste de cubo. A correção do teste respeitou a instrução do manual do WISC III.

\subsubsection{Consciência fonológica}

- Tarefa de Spoonerismo (adaptada por Cardoso-Martins, Haase, \& Wood, 1998, Phonological Assessment Battery, desenvolvida por Frederickson, Frith, \& Reason, 1997). A finalidade da tarefa é medir a manipulação de fonemas. A tarefa é dividida em duas partes, cada uma consta com três itens de treinamento e 10 itens experimentais. Na primeira, o objetivo é a manipulação do fonema inicial da palavra para a formação de uma nova palavra. Por exemplo, o fonema $/ \mathrm{g} /$, na palavra "gato", trocado por $/ r /$, forma a palavra rato. Na segunda parte, acontece a troca dos fonemas iniciais entre si de uma palavra composta, para a formação de duas pseudopalavras. Por exemplo, "milho verde" transforma-se em "vilho merde". A confiabilidade do teste é cronbach's alpha $=0.85$. Neste estudo, foi usada apenas a primeira parte da tarefa. Para cada acerto, foi marcado um ponto, perfazendo um total de 10 pontos. 


\subsubsection{Consciência morfológica}

- Tarefa de analogia (Nunes et al., 1997): essa tarefa tem como finalidade analisar a capacidade da criança em manejar os morfemas. A tarefa foi adaptada, considerando a especificidade da morfologia derivacional e flexional da língua portuguesa. Alguns itens foram retirados da adaptação para morfologia derivacional de Justi e Roazzi (2012), com índice de confiabilidade aceitáveis ( $a=0,65)$; Mota, Santos e Guimarães (2014), para morfologia derivacional $(a=0,59)$ e flexional $(a=0,61)$, ambos com índices aceitáveis de confiabilidade. A tarefa foi dividida entre itens que avaliam a morfologia derivacional e flexional. A tarefa de analogia derivacional conta com 3 itens de treinamento e 17 itens experimentais. Os itens experimentais são compostos por palavras com morfemas derivacionais sem mudança de classe gramatical (sufixos -eiro, -ada, -aria, -ista e -or) e os prefixos (em-, re-, im- e des-) e por morfemas com mudança gramatical (sufixos -oso, -eza, -ez, -ice e as terminações verbais -ar, -er e -ir). Para cada item, a criança deve ser capaz de formar uma palavra morfologicamente complexa a partir de uma palavra alvo. Por exemplo, belo- beleza, puro-? Os critérios estabelecidos para correção contam com um ponto para cada acerto e zero ponto para cada erro, havendo total de 17 acertos. Já a tarefa de analogia flexional conta com 4 itens de treino e de 17 itens experimentais. Os itens experimentais são formados por morfemas de flexões de gênero (feminino/masculino), número (singular/plural), modo verbal (indicativo, subjuntivo), tempo verbal (presente/passado/futuro) e pessoa ( $1^{a}$ e $3^{a}$ singular-presente; $1^{a}$ e $3^{a}$ singular- passado). Para cada item correto, é dado um ponto e para cada erro, zero pontos. Os critérios estabelecidos para correção contam com um ponto para cada acerto e zero ponto para cada erro. O total é de 17 pontos.

Confiabilidade e Validade das tarefas de Analogia. As análises do índice de consistência interna (Cronbach's) das tarefas de analogia mostraram-se adequados (Nunes \& Primi, 2010; Urbina, 2007) com a $=0,86$ para analogia derivacional e $\mathrm{a}=0,85$ para analogia flexional. As correlações das tarefas de analogia com a tarefa de consciência fonológica mostraram-se significativas e moderadas, analogia derivacional $r=0,62, p<0,001$ e analogia flexional $r=0,67, p<0,001$. Então, as medidas de analogia derivacional e flexional tiveram alta consistência interna e moderadas correlações com a tarefa de consciência fonológica.

\subsubsection{Escrita}

- Ditado experimental de palavras. O ditado foi adaptado de Justi (2009) e Barbosa (2013). As palavras modificadas do ditado de Justi (2009) foram retiradas da lista de Pinheiro (1996). O ditado foi 
dividido em 3 categorias de-diferenças ortográficas. Categoria 1palavras com regras contextuais. Ditado com 16 palavras ( 8 frequentes e 8 infrequentes). Nesse grupo de palavras é o contexto, dentro da palavra, que vai determinar qual letra (ou dígrafo) deverá ser usada. Por exemplo, o uso do som $/ r /$ representado pelo dígrafo $r r$ entre vogais (como carro e serrote), mas pela letra $r$ em outros contextos (como careca e braço). Categoria 2- palavras com regras morfológicas. Ditado com 12 palavras com regras morfológicas ( 5 frequentes e 7 infrequentes). Por exemplo, a regra segundo a qual 0 som /iw/ no final da palavra é representado pela sequência de letras il, se a palavra é um substantivo (por exemplo, mil), mas pela sequência iu, se a palavra é um verbo (por exemplo, cumpriu). Categoria 3- palavras irregulares, sem regras. Ditado com 20 palavras, divididas em 10 frequentes e 10 infrequentes, com ortografias irregulares. Por exemplo, o uso do fonema $/ \mathrm{S} /$ pode ser representado pela letra $x$ ou pelo dígrafo $c h$, independentemente do contexto em que ocorre e da categoria gramatical da palavra. Na correção, foi atribuído um ponto para cada acerto.

Confiabilidade do ditado experimental. As análises de consistência interna (Cronbach's) das palavras com regras contextuais apresentaram bons índices $(a=0,79)$ e nas palavras com regras morfológicas $(a=0,55)$ e palavras irregulares $(a=0,63)$, os índices foram moderados (Nunes \& Primi, 2010; Urbina, 2007).

\subsection{Procedimentos}

As avaliações aconteceram na própria escola, em três sessões individuais de aproximadamente 40 minutos com cada criança, além de uma sessão coletiva. Na primeira sessão, foi realizado o teste de habilidade não verbal WISCIII: subteste de cubos. Na segunda sessão, a aplicação das tarefas de consciência fonológica e morfológica. Na terceira sessão, aplicação do WISCII: subteste de vocabulário. Na última sessão, coletiva, as crianças realizaram o ditado na própria sala de aula.

\subsection{Resultados}

As médias e os desvios padrões de todas as medidas usadas são apresentados na tabela 1 . Os dados de cada distribuição foram conferidos quanto à normalidade, através da divisão das skewness pelo desvio padrão do erro (Fidel, 2009). Essa verificação mostrou que a distribuição da ortografia de palavras com regras contextuais, consciência fonológica, vocabulário e cubo tiveram problemas na skewness, -6, 47, -2,2, 2,4 e 4,4, respectivamente. Para resolver 0 problema, usamos a transformação logarítmica, Ln (valor máximo + 1- escores da variável), nas distribuições assimétricas negativas, e a 
transformação por radiciação ( escores da variável), nas assimétricas positivas (Field, 2009). Em todas as análises foram usadas as variáveis transformadas.

Tabela 1

Estatísticas Descritivas e Fidedignidade das Tarefas Administradas

\begin{tabular}{lccc}
\hline \multicolumn{1}{c}{ Tarefas } & Escore total & $\mathrm{M}$ & DP \\
\hline Consciência fonológica & 10 & 5,9 & 3 \\
Consciência morfológica derivacional & 17 & 8,4 & 3,9 \\
Consciência morfológica flexional & 17 & 9,7 & 4,2 \\
Palavras com regras contextuais & 16 & 13,1 & 2,8 \\
Palavras com regras morfológicas & 12 & 7,9 & 2,2 \\
Palavras irregulares & 20 & 13,5 & 3 \\
Vocabulário/ WISCIII (escore ponderado) & - & 11 & 3,7 \\
Cubo/ WISC III (escore ponderado) & - & 9,6 & 3,6 \\
\hline
\end{tabular}

Tabela 2

Correlações (Pearson) entre as variáveis.

\begin{tabular}{|c|c|c|c|c|c|c|c|c|c|}
\hline & 1 & 2 & 3 & 4 & 5 & 6 & 7 & 8 & 9 \\
\hline \multicolumn{10}{|l|}{ 1-PRM } \\
\hline 2-PI & $0,61 * *$ & & & & & & & & \\
\hline 3-PRC & $0,61^{* *}$ & $0,66^{* *}$ & & & & & & & \\
\hline 4- $\mathrm{CF}$ & $0,53 * *$ & $0,58 * *$ & $0,59 * *$ & & & & & & \\
\hline 5- CMD & $0,52^{* *}$ & $0,59 * *$ & $0,52^{* *}$ & $0,62^{* * *}$ & & & & & \\
\hline 6- $\mathrm{CMF}$ & $0,49^{* *}$ & $0,58 * *$ & $0,57^{* *}$ & $0,67^{* *}$ & $0,72^{* *}$ & & & & \\
\hline 7-Vocabulário & 0,02 & 0,03 & 0.13 & 0,15 & 0,18 & $0,19^{*}$ & & & \\
\hline 8-Cubo & $0,46 * *$ & $0,30 * *$ & $0,35 * *$ & $0,38 * *$ & $0,41^{* *}$ & $0,43 * *$ & 0,42 & & \\
\hline 9-Idade & $0,55^{\mathrm{k*}}$ & $0,47^{\mathrm{k*}}$ & $0,38 * *$ & $0,43^{* *}$ & $0,38^{* * *}$ & $0,49^{* * *}$ & $0,26^{* * *}$ & $0,41^{* *}$ & \\
\hline
\end{tabular}

Nota. $P R M=$ palavras com regras morfológicas; $P I=$ palavras irregulares; $P R C=$ palavras com regras contextuais; $C F=$ consciência fonológica; $C M D=$ consciência morfológica derivacional; $C M F=$ consciência morfológica flexional; ** $p<0,01$.

As correlações de Pearson entre as variáveis são apresentadas na tabela 2. Como se pode observar, na tabela 2, a idade, as tarefas de consciência morfológica e fonológica correlacionaram, de maneira positiva, moderada e significativa $(p<0,01)$ com todas as variáveis de escrita. O vocabulário não correlacionou, de maneira significativa, com as variáveis da escrita. Por isso, nas próximas análises estatísticas, o vocabulário não será usado. 


\subsection{Efeito da consciência morfológica nos diversos tipos de ortografia no português}

As análises de regressão hierárquica foram conduzidas para investigar se a consciência morfológica é uma variável preditora da escrita, depois de controlados os efeitos da idade, das habilidades não verbais e da consciência fonológica. Em cada uma das regressões hierárquicas, foram realizados os seguintes passos: $1^{0}$ - a idade $e$ habilidade não verbal (cubo/WISCIII)), 20 - a consciência fonológica e $3^{0}$ - a consciência morfológica.

Os resultados das análises de regressão são apresentados na tabela 3. A consciência morfológica derivacional explicou $2,5 \%$ e a flexional $3,4 \%$ da variância das palavras com regras contextuais. A consciência morfológica derivacional explicou $7,4 \%$ e a flexional $4 \%$ da variância das palavras irregulares. Apenas a consciência morfológica derivacional explicou de forma significativa a variância das palavras com regras morfológicas $(2,5 \%)$. Esses resultados mostram que, mesmo após o controle da idade, cubo/WISCIII e consciência fonológica, a consciência morfológica ainda contribui, de maneira independente, para explicar a escrita dos diferentes tipos de regras ortografia.

Tabela 3

Resumo dos resultados das análises de regressão hierárquica.

\begin{tabular}{|c|c|c|c|c|c|c|}
\hline \multirow{3}{*}{$\begin{array}{c}\text { Passos/ } \\
\text { Variáveis } \\
\text { Preditivas }\end{array}$} & \multicolumn{2}{|c|}{ Contextual } & \multicolumn{2}{|c|}{ Morfológica } & \multicolumn{2}{|c|}{ Irregular } \\
\hline & $\Delta \mathrm{R}^{2}$ & $\beta$ & $\Delta \mathrm{R}^{2}$ & $\beta$ & $\Delta \mathrm{R}^{2}$ & $\beta$ \\
\hline & & & & & & \\
\hline $\begin{array}{l}1^{\circ} \text { Idade } \\
\text { Cubo/WISIII. }\end{array}$ & $0,19 * * *$ & & $0,37 * * *$ & & $0,23 * * *$ & \\
\hline $2^{\circ} \mathrm{CF}$ & $0,19 * * *$ & & $0,074^{* *}$ & & $0,17 * * *$ & \\
\hline $3^{\circ} \mathrm{a} \mathrm{CMD}$ & $0,025^{*}$ & $0,21^{*}$ & $0,025^{* *}$ & $0,21^{*}$ & $0,074^{* * *}$ & $0,36^{*}$ \\
\hline $3 \% \mathrm{CMF}$ & $0,034^{*}$ & $0,26^{*}$ & 0,001 & 0,12 & $0,040 * *$ & $0,28 *$ \\
\hline $2^{\circ} \mathrm{CM}$ & $0,18^{* * *}$ & & $0,075^{* *}$ & & $0,22 * * *$ & \\
\hline $3^{\circ} \mathrm{CF}$ & $0,054 * *$ & $0,33^{*}$ & $0,026^{*}$ & $0,23^{*}$ & $0,029^{*}$ & $0,24 * *$ \\
\hline
\end{tabular}

\subsection{Efeito da consciência fonológica nos diversos tipos de ortografia no português}

Para compreender se a consciência morfológica tem uma contribuição maior do que a fonológica na escrita foram realizadas novas análises de regressão hierárquica. Assim, para verificar a influência da consciência fonológica para cada variável de escrita (palavras com 
regras contextuais, palavras com regras morfológicas e palavras irregulares) alterou-se a ordem da entrada das variáveis. Cada uma das regressões hierárquicas de ordem fixa foi realizada com os seguintes passos: $1^{0}$ passo - idade e cubo/ WISCIII; $2^{\circ}$ passo consciência morfológica derivacional e flexional e $3^{\circ}$ passo consciência fonológica.

Os resultados das análises de regressão são apresentados na tabela 3. A consciência fonológica contribuiu, de maneira positiva, significativa e independente, com as variáveis de controle. Sua contribuição foi de cerca de $5,4 \%$, para as palavras com regras contextuais, 2,6\%, para as palavras com regras morfológicas, e $2,9 \%$, nas palavras irregulares.

A contribuição da consciência fonológica foi maior do que a morfológica nas palavras com regras contextuais e morfológicas. Nas palavras irregulares, a contribuição da consciência morfológica foi maior do que a consciência fonológica.

\section{Discussão}

Este artigo foi desenhado para responder a duas perguntas. A contribuição da consciência morfológica é única e para além da consciência fonológica em palavras com diferentes regras ortográficas no português? A influência da consciência morfológica é maior do que o da consciência fonológica?

Em relação à primeira pergunta, a consciência morfológica derivacional e flexional contribuíram de forma única para as palavras irregulares e de regras contextuais e a consciência morfológica derivacional contribuiu de maneira significativa para a escrita de regras morfológicas.

Esses achados corroboram com estudos anteriores que indicam uma conexão entre consciência morfológica e escrita, independente da influência da consciência fonológica (Conti, 2010; Deacon et al., 2009; Justi, 2009; Mota et al., 2008; Nunes et al., 1997), principalmente com palavras com regras morfológicas (Conti, 2010; Justi, 2009). Além disso, amplia a discussão para o alcance da influência da consciência morfológica na ortografia de palavras com regras contextuais e irregulares, efeito este não encontrado por Justi (2009) e Conti (2010).

Com base nos resultados das análises de regressão hierárquica, as respostas para a segunda questão dependem do tipo da ortografia da palavra. Nas palavras com regras contextuais, a despeito de a consciência morfológica ter tido uma contribuição única e significativa, essa contribuição não foi maior do que da consciência fonológica. Nas palavras irregulares, a contribuição da consciência morfológica derivacional e flexional foi maior do que a consciência 
fonológica. Uma possível explicação para esses resultados está nas características ortográficas dessas palavras. Palavras com regras contextuais obedecem a uma certa regularidade na correspondência entre letra e som. Por exemplo, antes de "p" e "b", é sempre grafado " $\mathrm{m}$ " para representar o som nasal. Assim, é possível que os alunos que conhecem as regras de correspondência entre letra e som assimilem essas regras também. Já as palavras irregulares fogem às regras e, nesse caso, o conhecimento dos morfemas passa a ter importância na escolha da grafia das palavras.

Nas palavras com regras morfológicas, a consciência fonológica teve uma influência um pouco acima da morfológica. Embora se esperasse uma contribuição maior da consciência morfológica derivacional do que da fonológica ambas fizeram contribuições significativas e únicas para escrita dessas palavras. Os morfemas seguem regras bem regulares de escrita no português, ou seja, o processamento das regras de correspondência entre letra e som pode ajudar na aquisição dessas regras morfológicas interagindo com elas. No entanto, tratase de uma questão que precisa de maior investigação.

O avanço na ortografia pode estar relacionado à percepção da criança de que nem sempre as relações entre sons e letras são perfeitas. No caso da língua portuguesa, há muitas palavras com complexidade ortográfica, forçando as crianças a ampliaram a reflexão sobre a linguagem escrita para além das estratégicas fonológicas. Por exemplo, a palavra "perigoso" tem a última consoante com som /z/, mas se escreve com a letra " $\mathrm{s}$ ". Nesse sentido, se a criança recorrer apenas à consciência fonológica para escrever a palavra "perigoso", provavelmente não irá fazê-lo de modo correto.

Os resultados deste estudo sugerem que as crianças manipulam de maneira deliberada tanto os fonemas quanto os morfemas, para escrever as palavras com diferentes tipos de ortografia. Dessa maneira, esses achados contribuem para conceituações teóricas atuais de desenvolvimento da escrita (Ehri, 2005; Seymour, 2005), ao demonstrarem que o pensamento consciente/ explícito sobre os morfemas que compõem as palavras são estratégias cognitivas primordiais, para as crianças superarem as complexidades ortográficas e avançarem no desenvolvimento ortográfico.

Enfim, nesta perspectiva, acredita-se que os resultados aqui apresentados potencializam evidências de que a consciência morfológica pode ter um papel importante, assim como a consciência fonológica no desenvolvimento ortográfico.

Uma limitação do presente estudo foi o tamanho da amostra. 0 segundo e quarto anos foram agrupados para que pudéssemos incluir todos os controles necessários. Há evidências na literatura de que a consciência morfológica contribui para leitura e escrita desde os anos iniciais do Ensino Fundamental, mas essa contribuição pode variar ao longo dos anos escolares (Mota et al., 2011). Assim, estudos futuros 
devem avaliar também mudanças no desenvolvimento da consciência morfológica.

\section{Considerações finais}

Propôs-se, neste estudo, estabelecer se há uma contribuição da consciência morfológica e da escrita. Os resultados sustentam a importância da consciência morfológica para o desempenho na escrita. Isso nos motiva a considerar o potencial valor de ensinar explicitamente as crianças sobre morfemas nas escolas. Entretanto, estudos que combinem delineamento longitudinal e intervenção são os únicos que podem suscitar um nível mais preciso da relação causa e efeito (Nunes \& Bryant, 2006). Assim, pesquisas futuras no âmbito nacional devem levar em conta esses desenhos metodológicos, no intuito de ampliarem o conhecimento sobre as interações do papel da consciência morfológica nos processos de leitura e escrita no português.

\section{Referências}

Barbosa, V. (2013). O papel da consciência morfológica no aperfeiçoamento da linguagem escrita (Tese de doutorado não publicada). Programa de Pós-Graduação em Educação da Universidade do Paraná, Curitiba.

Bechara, E. (2009). Moderna Gramática Portuguesa (37. ed.). Rio de Janeiro: Novas Fronteiras.

Bowers, P., Kirby, J., \& Deacon, S. H. (2010). The Effects of Morphological Instruction on Literacy Skills: A Systematic Review of the Literature. Review of Educational Research, 80(2), 144179. doi: $10.3102 / 0034654309359353$.

Bradley, L., \& Bryant, P. (1983). Categorizing sounds and learning to read - a causal connection. Nature, 301, 419-421. doi: $10.1038 / 301419 \mathrm{a} 0$.

Cardoso-Martins, C. (1995). Consciência fonológica e alfabetização. Petrópolis: Vozes.

Cardoso-Martins, C., Haase, V., \& Wood, G. (1998). Bateria de testes de habilidades fonológicas adaptada da Phonological Assessment Battery. Manuscrito não-publicado.

Carlisle, J. (1995). Morphological awareness and early reading achievement. In L. Feldman (Ed.), Morphological aspects of language processing (pp. 271-292). Hillsdale: Lawrence Erlbaum Associates. 
Carlisle, J. (2010). Effects of instruction in morphological awareness on literacy achievement: an integrative review. Reading Research Quarlety, 45(4), 464-485.

Conti C. (2010). A relevância da consciência metalinguística na ortografia de palavras morfologicamente complexas na língua portuguesa (Dissertação de mestrado). Programa de PósGraduação em Psicologia da Universidade Federal de Juiz de Fora, Juiz de Fora.

Deacon, S. H., Kirby, J., \& Casselman-Bell, M. (2009). How robust is the contribution of morphological awareness to general spelling outcomes? Reading Psychology, 30, 301-318. doi: 10.1080/02702710802412057.

Ehri, L. (2005). Development of sight word reading: phases and findings. In M. Snowling, \& C. Hulme (Eds). The Science of Reading: a handbook. Malden, MA: Blachwell Publishing.

Field, A. (2009). Descobrindo estatística usando o SPSS (2. ed.). Porto Alegre: Armed.

Fredrickson, N., Frith, U., \& Reason, R. (1997). Phonological Assessment Battery Standardised Edition. London: NFER-Nelson.

Gombert, J. (2003). Atividades metalinguísticas e aprendizagem da leitura. In M. R. Maluf. Metalinguagem e aquisição da escrita: contribuições da pesquisa para a prática de alfabetização (pp. 1963). São Paulo: Casa do Psicólogo.

Goodwin, \& Ahn (2010). A meta-analysis of morphological interventions: effects on literacy achievement of children with literacy difficulties. Annals of Dyslexia, 60, 183-208. Doi: 10.1007/s11881-010-0041-x

Justi, C. (2009). A contribuição do processamento fonológico, da consciência morfológica e dos processos subjacentes à nomeação seriada rápida para a leitura e a escrita no português brasileiro (Tese de doutorado não publicada). Programa de Pós-Graduação em Psicologia Cognitiva da Universidade Federal de Pernambuco, Recife.

Justi, C., \& Roazzi, A. (2012). A Contribuição de Variáveis Cognitivas para a Leitura e a Escrita no Português Brasileiro. Psicologia: Reflexão e Crítica, 25(3), 605-614. doi: 10.1590/S010279722012000300021.

Laroca, M. (2005). Manual de morfologia do português. Campinas: Pontes.

Maluf, M., \& Barrera, S. (1997). Consciência fonológica e linguagem escrita em pré-escolares. Psicologia Reflexão e Crítica, 10(1), 125-145. doi: 10.1590/S0102-79721997000100009.

Mann, V. A., \& Liberman, I. Y. (1984). Phonological awareness and verbal short-term memory. Journal of Learning Disabilities, 17, 592-598. doi: 10.1177/002221948401701005. 
Mota, M., Anibal, L., \& Lima, S. (2008). A morfologia derivacional contribui para a leitura e escrita no português? Psicologia: Reflexão e Crítica, 21(2), 311-318. doi: 10.1590/S010279722008000200017.

Mota, M., Besse, A-S., Dias, J., Paiva, N., Mansur-Lisboa, S. \& Silva, D. A. (2011). O Desenvolvimento da Consciência Morfológica nos Estágios Iniciais da Alfabetização. Psicologia: Reflexão e Crítica, 24(1), 144-150. doi: 10.1590/S0102-79722011000100017.

Mota, M., Santos, A., \& Guimarães, S. (2014). Evidências de validade e consistência interna de tarefas de analogia gramatical. Estudos de Psicologia, 19(4), 250-257. doi: 10.1590/S1413294X2014000400002.

Nunes, C. H. S., \& Primi, R. (2010). Aspectos técnicos e conceituais da ficha de avaliação dos testes psicológicos. In Conselho Federal de Psicologia - CFP (Org.), Avaliação psicológica: Diretrizes na regulamentação da profissão (pp. 101-128). Brasília: CFP.

Nunes, T., Bindman, M., \& Bryant, P. (1997). Morphological strategies: Developmental stages and processes. Developmental Psychology, 33(4), 637-649. Retirado de http://bobhall.tamu.edu/epsy602/Topics/Articles/Bryant1997.pdf

Nunes, T., \& Bryant, P. (2006). Improving Literacy by Teaching Morphemes. Abingdon-on-Thames: Routlege.

Nunes, T., Bryant, P., \& Olsson, J. (2003). Learning Morphological and Phonological Spelling Rules: An Intervention Study. Scientific Studies in Reading, 7(3), 289-307. doi: 10.1207/S1532799XSSR0703_6.

Pinheiro, A. (1996). Contagem de frequência de ocorrência e análise psicolinguística de palavras expostas a crianças na faixa préescolar e séries iniciais do $1^{\circ}$ grau. São Paulo, SP: Associação Brasileira de Dislexia.

Reed, D. K. (2008). A synthesis of morphology interventions and effects on reading outcomes for students in Grades $\mathrm{K}-12$. Learning Disabilities Research \& Practice, 23(1), 36-49. doi: 10.1111/j.1540-5826.2007.00261.x.

Seymour, P. (2005). Early reading development orthographies in european In M. Snowling \& C. Hulme (Eds), The Science of Reading: a handbook. Malden, MA: Blachwell Publishing.

Seymour, P., Aro, M., \& Erskine, J. M. (2003). Foundation literacy acquisition in European orthographies. British Journal of Psychology, 94(2), 143-174. doi: $10.1348 / 000712603321661859$.

Stein, L. (1994). Teste de Desempenho Escolar. São Paulo, SP: Casa do Psicólogo.

Urbina, S. (2007). Fundamentos da testagem psicológica. Porto Alegre: Artmed. 
Wechsler, D. (1991). WISC-III: Escala de inteligência Weschsler para crianças. São Paulo: Casa do Psicólogo.

\section{Endereço para correspondência \\ Silvia Brilhante Guimarães}

Rua Senador Vergueiro, 148/904, Flamengo, CEP 22230-001, Rio de Janeiro - RJ, Brasil

Endereço eletrônico: silvia_brilhante@yahoo.com.br

\section{Márcia Maria Peruzzi Elia da Mota}

Universidade do Estado do Rio de Janeiro - UERJ

Programa de Pós-Graduação em Psicologia Social

Rua São Francisco Xavier, 524, sala 10006 bloco D, Maracanã, CEP 20550-900, Rio de Janeiro - RJ, Brasil

Endereço eletrônico: mmotapsi@pesquisador.cnpq.br

Recebido em: $28 / 10 / 2015$

Reformulado em: $14 / 02 / 2018$

Aceito em: 18/02/2018

\section{Notas}

* Pós-doutoranda em Psicologia pela Universidade Salgado de Oliveira.

** Docente do Programa de Pós-Graduação da Universidade Salgado de Oliveira e do Programa de Pós-Graduação em Psicologia Social da UERJ, Rio de Janeiro, Brasil, doutora em Psicologia pela Universidade de Oxford, bolsista de produtividade do CNPq.

Este artigo de revista Estudos e Pesquisas em Psicologia é licenciado sob uma Licença Creative Commons Atribuição-Não Comercial 3.0 Não Adaptada. 